\title{
NGF and NT-3 Have Differing Effects on the Growth of Dorsal Root Axons in Developing Mammalian Spinal Cord
}

\author{
Li Zhang, ${ }^{1}$ Robert E. Schmidt,, ${ }^{2}$ Qiao Yan, ${ }^{3}$ and William D. Snider ${ }^{1}$ \\ ${ }^{1}$ Center for the Study of Nervous System Injury, Department of Neurology, and ${ }^{2}$ Department of Pathology, Washington \\ University Medical School, St. Louis, Missouri 63110, and ${ }^{3}$ Amgen Center, Thousand Oaks, California 91320-1789
}

The functions of neurotrophins in relation to axon growth and branching during development of the nervous system are unknown. In order to address this question, we have investigated the influences of systemically administered mouse nerve growth factor (mNGF) and human recombinant neurotrophin-3 (hrNT-3) on dorsal root axon growth in the spinal cord of embryonic rats. As anticipated, mNGF has a marked influence on growth of dorsal root axons. In mNGF. treated animals, dorsal root axons in the developing dorsal funiculi and axon collaterals in developing gray matter are substantially longer than those of age-matched controls. Furthermore, growth cones of some dorsal root axons have more than twice the surface area of controls. These effects of NGF are highly selective. Dorsal root axons that occupy a lateral position in white matter and that normally give off collaterals to superficial dorsal horn are prominently affected. Axons that run medially in dorsal columns and that give off collaterals to laminae III and IV and the ventral horn are not demonstrably influenced by treatment with exogenous mNGF.

In contrast to the striking effects of mNGF on dorsal root axon growth, the influences of hrNT-3 were considerably more complex. Administration of hrNT-3 increased the mean soma area of DRG neurons, particularly those at the larger end of the size spectrum, consistent with its hypothesized role as a growth factor for proprioceptive sensory neurons. However, in striking contrast to the actions of mNGF, hrNT-3 consistently inhibited axon collateral growth in gray matter at early developmental stages. At later stages, we could not discern a clear-cut influence of hrNT-3 on dorsal root axon growth and branching.

We conclude that the ability of mNGF to stimulate axon growth in both white and gray matter is consistent with the idea that mNGF regulates the developing axonal projections of DRG neurons in vivo. In contrast, systemically administered hrNT-3 inhibits the axon collateralizations of DRG neurons in gray matter at early developmental stages. We hy-

\footnotetext{
Received Nov. 17, 1993; revised Feb. 23, 1994; accepted Mar. 24, 1994.

This work was supported by NS31768 to W.D.S., AG 10299, DK19645 to R.E.S., and Program Project NS17763. We thank Dr. E. M. Johnson, Jr. and P. Osborne for the generous gift of mNGF. We thank E. M. Johnson, Jr., I. SilosSantiago, C. Sanner, D. Wright, J. Elliott, and A. Konstantinidou for helpful comments on the manuscript. We thank Jeff Hogan for the purification of hrNT-3 and hrBDNF, and Dr. Santiago B. Plurad for excellent technical assistance.

Correspondence should be addressed to William D. Snider, M.D., Department of Neurology, Box 8111 , Washington University, School of Medicine, 660 South Euclid Avenue, St. Louis, MO 63110.

Copyright (C) 1994 Society for Neuroscience $0270-6474 / 94 / 145187-15 \$ 05.00 / 0$
}

pothesize that this inhibitory effect may be related to disruption of a chemotropic gradient of NT-3, or to the widespread expression of the NT-3 receptor trkC, on non-neuronal cells.

[Key words: neurotrophins, dorsal root axons, growth cones, dorsal funiculi, spinal cord development]

The remarkable ability of NGF to promote neurite outgrowth from sensitive neuronal populations was the key activity that led to its purification (see Levi-Montalcini and Angeletti, 1968, for a review). Neurite outgrowth remains in common use as a bioassay for NGF, and more recently described members of the neurotrophin family share this activity. Neurite outgrowth induced by NGF is equally impressive in vivo and has been documented in both the PNS and CNS (Levi-Montalcini and Hamburger, 1951; Olson et al., 1967; Menesini-Chen et al., 1978; Hagg et al., 1992; Kawaja et al., 1992). Surprisingly, the precise functions subserved by this neurite outgrowth-promoting activity during development are unknown. Three functions have been proposed: (1) growth factors regulate neural differentiation and axon growth is a concomitant of the differentiation program (see Snider and Johnson, 1989, for a review); (2) growth factors attract growing axons into target fields (chemotropism) (Menesini-Chen et al., 1978; Tessier-Lavigne et al., 1988; Bolz et al., 1990; Heffner et al., 1990; Tessier-Lavigne and Placzek, 1991; see also Gunderson and Barrett, 1979, 1980); and (3) growth factors regulate the density of axon branching and synaptic rearrangement in target fields during development (Olson et al., 1967; Korsching and Thoenen, 1983; Shelton and Reichardt, 1984; Maffei et al., 1992). There is currently insufficient experimental evidence to conclude whether any or all of these theories may be correct. Investigations on whether growth factors regulate the growth of axons have lagged behind studies on other aspects of growth factor function, primarily because such effects are more difficult to visualize and quantitate (Ruit et al., 1992). A further difficulty in the case of axon growth is that it is desirable to assess effects in embryonic life when axons are growing toward their targets, a fact that complicates the delivery of growth factors and their antibodies.

In the present study we have characterized the influence of three neurotrophins on axon growth in the embryonic rat spinal cord in vivo. We have chosen the DRG system because all known neurotrophins promote survival and neurite outgrowth of DRG neurons in vitro (Davics ct al., 1986; Leibrock et al., 1989; Hohn et al., 1990; Maisonpierre et al., 1990; Berkemeier et al., 1991). Furthermore, human recombinant BDNF and NT-3 have recently become available in quantities adequate for in vivo ex- 
periments. In order to assess the effects of neurotrophins, we have stained the DRG projection with the intensely fluorescent, lipid-soluble tracer DiI, which fully stains axons and their branches in fixed tissue (Honig and Hume, 1986; Godement et al., 1987). We have delivered neurotrophins at an early stage prior to the arrival of DRG axons in their target fields using a well-established protocol of direct injections in utero (Kessler and Black, 1980; Goedert et al., 1984; Johnson et al., 1989; Ruit et al., 1992).

We show here that mNGF strikingly enhances dorsal root axon growth in both white and gray matter of the developing rat spinal cord. Furthermore, growth cones of particular populations of dorsal root axons have more than twice the surface area of controls. Finally, the effects of $\mathrm{mNGF}$ are selective for axons that run laterally in dorsal white matter and normally terminate in the superficial dorsal horn. In contrast, effects of hrBDNF and hrNT-3 on axon growth were considerably more complex, and hrNT-3 consistently inhibited axon collateral branching in spinal gray matter at early developmental stages. We hypothesize that these inhibitory effects of hrNT-3 may be related to the widespread expression of a truncated form of the NT-3 receptor trk $\mathrm{C}^{\mathrm{TK}-}$ by non-neuronal cells or to disruption of a chemotropic gradient involving NT-3.

\section{Materials and Methods}

Neurotrophins. Mouse NGF, purified according to a standard protocol (Bocchini and Angeletti, 1969), was generously provided by E. M. Johnson, Jr. and P. Osborne. Recombinant human BDNF and NT-3 were produced in Escherichia coli and transfected with BDNF or NT-3 expression vectors. BDNF and NT-3 were purified to homogeneity by the protein chemistry group at Amgen as previously described (Spina et al., 1992). The biological activities of BDNF and NT-3 were routinely assessed using a chicken DRG explant assay (Lindsay et al., 1985).

In utero injections. Pregnant Sprague-Dawley rats (Sasco, Omaha, $\mathrm{NE}$ and Harlan, Indianapolis, IN) at 14 or $15 \mathrm{~d}$ gestation were anesthetized with a cocktail of ketamine $\mathrm{HCl}$ (Vetalar; $100 \mathrm{mg} / \mathrm{ml}$ ), xylazine (Rompun; $20 \mathrm{mg} / \mathrm{ml}$ ), and acepromazine maleate (PromAce; $10 \mathrm{mg}$ / $\mathrm{ml}$ ) in a 3:3:1 mixture by volume. A $0.7 \mathrm{ml} / \mathrm{kg}$ dose of the cocktail was administered intramuscularly, resulting in a deep anesthesia. Individual embryos were injected in utero using methods previously outlined in detail (Ruit et al., 1992). Growth factors and control solutions were drawn up in a $50 \mu$ l Hamilton syringe with an attached 30 gauge needle. mNGF was dissolved with L15 (Sigma), and hrNT-3 and hrBDNF were dissolved with sterile $0.85 \%$ saline. Age-matched embryos used as controls in separate litters received injections of L15 (for $\mathrm{mNGF)} \mathrm{or} 0.85 \%$ saline (for hrNT-3 and hrBDNF).

Neurotrophins were administered by two separate injections, on E14 and E15, E15 and E16, or E15 and E17. Embryos were then taken individually by cesarean section at E16, E17, or E19, respectively. For $\mathrm{mNGF}, 10 \mu \mathrm{l}$ of a $1 \mathrm{mg} / \mathrm{ml}$ solution was injected into each embryo. For hrNT-3 and hrBDNF, $10 \mu \mathrm{l}$ of either a $0.25 \mathrm{mg} / \mathrm{ml}$ or a $0.5 \mathrm{mg} / \mathrm{ml}$ solution was injected. In our hands, embryos did not survive treatment with higher dosages of hrNT-3. It also should be noted that injections on E14 were associated with a high rate of fetal wastage $(\sim 75 \%)$.

DiI labeling. The embryos were anesthetized by hypothermia and perfused through the left ventricle with $4 \%$ paraformaldehyde in $0.1 \mathrm{M}$ phosphate buffer ( $\mathrm{pH}$ 7.4). After the embryos had been postfixed for 24 $\mathrm{hr}$, the spinal cords and DRGs were removed and small crystals of the intensely fluorescent, lipid-soluble tracer DiI $\left(1.1^{\prime}\right.$-dioctadecyl-3,3, $3^{\prime}, 3^{\prime}$ tetramethylindocarbocyanine perchlorate; Molecular Probes) were placed in DRGs according to methods outlined in detail previously (Ruit et al., 1992; Snider et al., 1992). In order to eliminate the intersegmental variability in the dorsal root projection, only the C5 (for transverse sections) or T6 (for parasagittal sections) DRGs were labeled. In some cases, in order to label the cutaneous dorsal root afferent projections selectively, large crystals of DiI were placed in the skin on the dorsum of the embryo. When the crystals were placed directly in the DRGs, specimens were kept in $10 \%$ formalin at $37^{\circ} \mathrm{C}$ from $5 \mathrm{~d}(\mathrm{E} 16$ and $\mathrm{E} 17)$ to $7 \mathrm{~d}$ (E19). For the skin preparations, incubation times ranged from $10 \mathrm{~d}$ to $14 \mathrm{~d}$.
The extent of DiI labeling of axons can be influenced by a variety of parametcrs including the sizc of the DiI crystal, composition of fixative, length of time in fixative prior to labeling, and temperature and length of time at which specimens are maintained (Godement et al., 1987; Snider and Palavali, 1990). It is important to note that all E 16 specimens were maintained in $10 \%$ formalin at $37^{\circ}$ for $5 \mathrm{~d}$ for both control and neurotrophin-treated groups. E19 specimens were maintained for $7 \mathrm{~d}$. A technical issue that could have affected our results is the potential for Dil to spread in the dorsal columns and funiculi to label axons that did not originate in the labcled DRG. In cxpcriments wherc this issue has been explicitly addressed, the evidence suggests that DiI does not spread to label adjacent unlabeled axons (Simon and O'Leary, 1992). Although we cannot exclude the possibility of spread to unintended axons, if such spread indeed occurred, there is no reason to suspect that it systematically occurred more or less often in neurotrophin-treated animals as compared to controls.

After the appropriate time interval, spinal cords were embedded in agar and sectioned on a vibratome in the transverse or parasagittal planes at $75 \mu \mathrm{m}$ thickness. Sections were photographed and suitable sections were selected for tracing by camera lucida. In many sections, photoconversion was carried out by utilizing $3,3^{\prime}$-diaminobenzidine tetrahydrochloride (DAB) according to a previously published protocol (Sandell and Masland, 1988; Snider et al., 1992).

In some preparations, axons in the dorsal and dorsolateral funiculi were visualized in an effort to quantitate the rate of axon growth in white matter. For these preparations, the spinal cord was first sectioned in the parasagittal orientation and the hemicord with the Dil-labeled C5 dorsal root and DRG attached was saved for visualization of DiIstained axons. Using iridectomy scissors, the dorsal and lateral funiculi were peeled away from the underlying gray matter, and flattened on a slide under a coverslip with the lateral surface up. This procedure allowed us to view all dorsal and dorsolateral funicular axons from the C5 DRG in a single section.

Quantitative analysis. Several aspects of neurotrophin actions on DRG neurons were quantitated. First, we assessed the influence of neurotrophins on DRG neuron soma cross-sectional area. For these studies, C5 DRGs were embedded in Araldite (Sigma, St. Louis, MO) as described previously (Ruit et al., 1992). Semithin $(1 \mu \mathrm{m})$ sections were cut in transverse orientation from each DRG and stained with toluidine blue. One section was selected from the central portion of each C5 DRG for tracing under camera lucida at $625 \times$. Even at this early age neurons were readily distinguishable from glia on morphological grounds. In order to lessen the possibility that profiles of larger cells were oversampled, only neurons with a nucleolus visible in the section were analyzed. $\mathrm{DRG}$ neuron somata profiles were then traced on a digitizing tablet interfaced with computer software designed to calculate areas (BIOQUANT, $\mathrm{R} \& \mathrm{M}$ Biomedics) and size-frequency histograms were generated. Because of the large number of experiments required to obtain numbers of cells needed for clear-cut conclusions about neuron size, we concentrated on the effects of mNGF and hrNT-3. For animals treated with hrNT-3, 1205 DRG neurons from 10 embryos from four separate litters were studied. For age-matched controls, 1318 DRG neurons from 12 embryos from five separate litters were analyzed. Three animals were treated with $\mathrm{mNGF}$, and $431 \mathrm{DRG}$ neurons from these animals were analyzed.

In order to determine the effects of $m N G F$ on axon growth in dorsal funiculi, we analyzed projected $35 \mathrm{~mm}$ photomicrograph negatives of whole-mount DiI-stained preparations taken at $10 \times$. Medial and lateral parts of dorsal funiculi were analyzed separately because different classes of axons enter the cord in different mediolateral locations. The rostral extension was divided into three parts yielding a total of six squares with dimensions $1.2 \times 1.2 \mathrm{~mm}$ each. The number of axons in each square was counted and scored as follows: 4, axon number $>100 ; 3$, axon number between 50 and $100 ; 2$, axon number between 25 and 50 ; 1 , axon number between 5 and $25 ; 0$, axon number $<5$.

Effects of mNGF on particular classes of dorsal root afferents were examined by measuring growth cone areas of dorsal root axons in preparation where axons could be traced from their entry zone in gray matter to their growth cones. Many of the best preparations were from skinlabeled material because fewer axons were labeled than in the preparations where DiI was placed in the DRG. Axons were placed into three rough categories: (1) axons projecting to the ventral horn (Ia afferents)the term "Ia" is used throughout to refer to the central axons of DRG neurons that innervate the primary endings of muscle spindles in the periphery and have monosynaptic contact on motor neurons (see Snider 

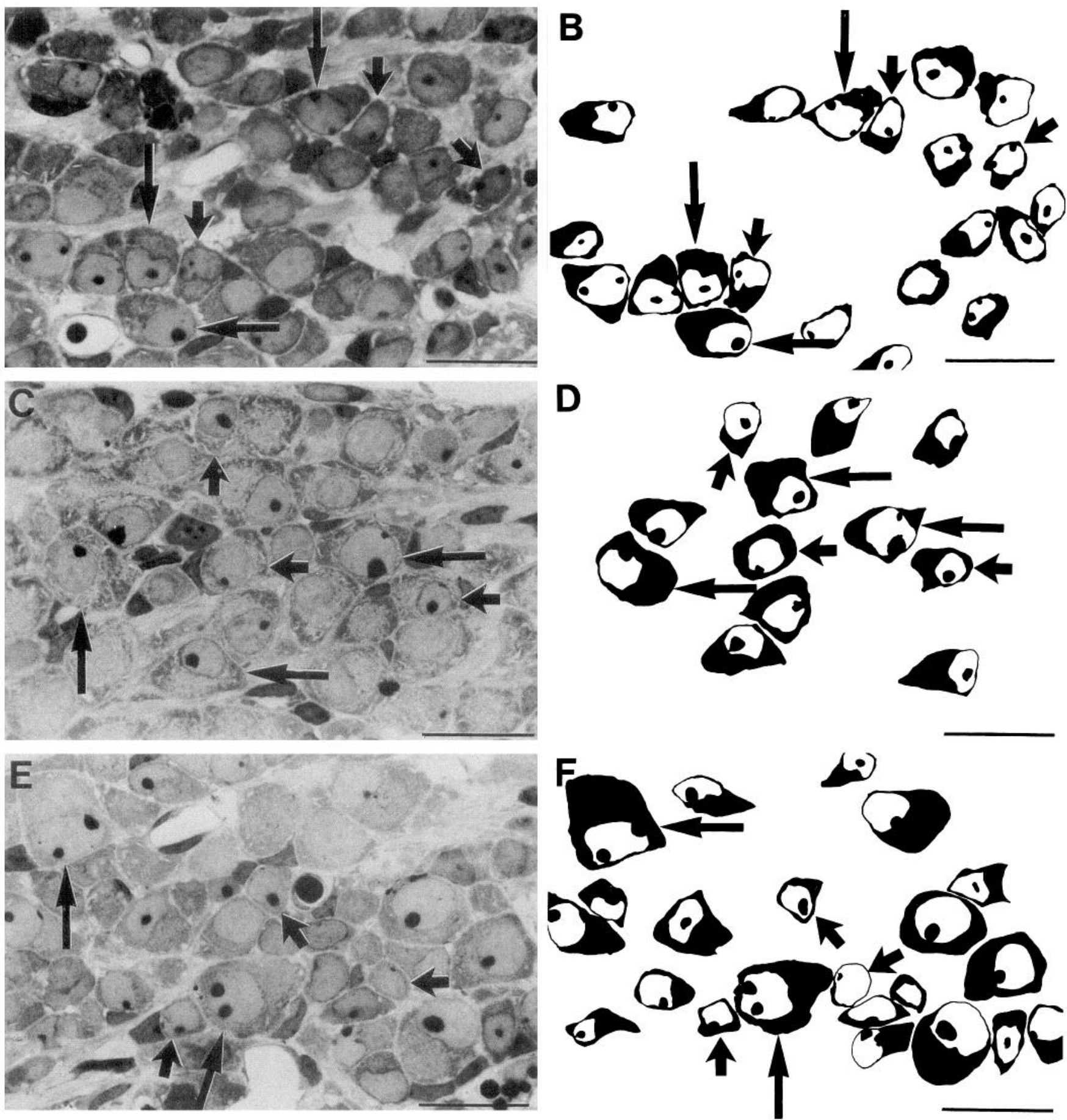

Figure 1. Semithin sections of C5 dorsal root ganglia at E16 from control and neurotrophin-treated animals. $A$ and $B$, Control. $C$ and $D$, mNGF treated. $E$ and $F$, hrNT-3 treated. Left, High-power photomicrographs $(1250 \times)$. Right, Camera lucida tracings of all neurons in left panels with nucleoli in the plane of section. Long arrows denote the largest neurons in the section, whereas short arrows denote the smallest. Control ganglia $(A, B)$ contain neurons of different sizes. $\operatorname{mNGF}(C, D)$ increased the size of small DRG neurons and thus made the ganglia appear more homogeneous. In contrast, hrNT-3 $(E, F)$ increased the size of larger neurons and thus accentuated cell size differences within the ganglion. Scale bars, $20 \mu \mathrm{m}$.

et al., 1992); (2) axons entering medially, projecting ventrally to laminae IV and $\mathrm{V}$, and turning upward to terminate in lamina III-many of these have the characteristic morphology of hair follicle afferents (see Snider et al., 1992, for a discussion); (3) fibers entering laterally and projecting ventrally or circumferentially - these latter fibers were confined to laminae $\mathrm{I}$ and $\mathrm{II}$ in control animals, although they projected somewhat more ventrally in mNGF-treated animals. Growth cones were traced and analyzed quantitatively in 17 photoconverted sections of C5 DRGs from four control animals and 16 sections of C5 DRGs from six mNGF-treated animals. At least 100 growth cones in each group were traced under camera lucida in control and mNGF-treated animals at $1250 \times$. Growth cone areas were determined by a computerassisted method using software for neuronal morphometry (BIOQUANT). Areas of growth cones in all of those groups were compared with agematched controls using one-way ANOVA (see Table 2). In a few experiments, surface areas of growth cones from animals treated with hrNT-3 were also computed.

Finally, we quantitated the length of fascicles of dorsal root axon 


\section{Composite}

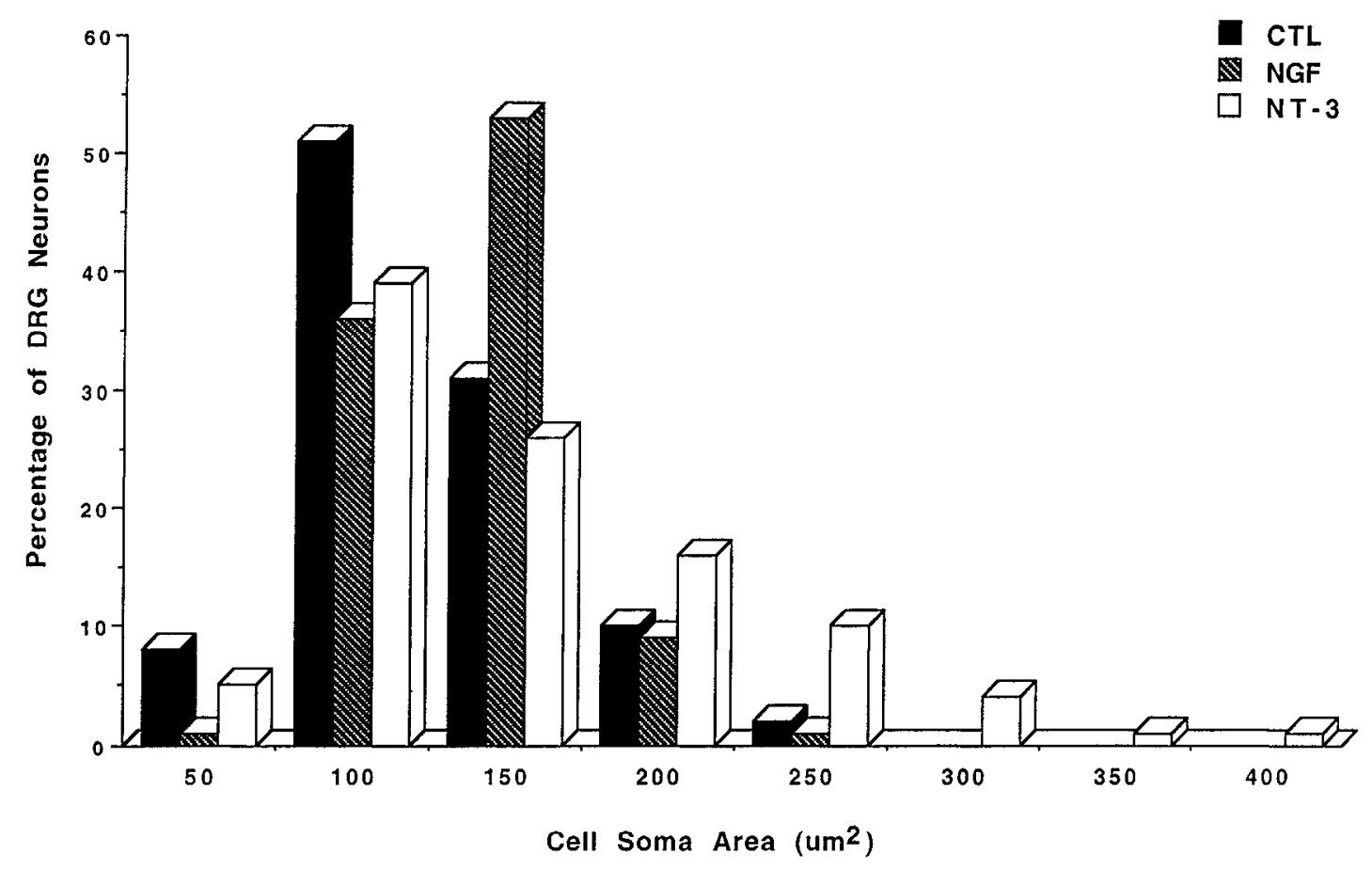

Figure 2. Histograms of DRG neuron soma areas at E16 in control and neurotrophin-treated animals generated using pooled data from neurons in all experiments. As expected, mNGF (hatched bars) had striking effects on DRG neuron size. The primary effects of mNGF treatment were to decrease the percentages of neurons in the $50 \mu \mathrm{m}^{2}$ and $100 \mu \mathrm{m}^{2}$ bins and to increase the percentage of neurons in the $150 \mu \mathrm{m}^{2}$ bin. Treatment with hrNt-3 (white bars) produced very different results. Neurons with areas between 50 and $150 \mu \mathrm{m}^{2}$ were slightly reduced in frequency compared to controls, whereas neurons between 150 and $200 \mu \mathrm{m}^{2}$ almost doubled in frequency. Note that less than $2 \%$ of DRG neurons in control animals have soma areas of $>200 \mu \mathrm{m}^{2}$ at E16. In contrast, almost $16 \%$ of DRG neurons in hrNT-3-treated animals were this large.

collaterals branching into gray matter at E16. The length of fascicles measured from dorsal funiculi to their maximum ventral extent was determined from photomicrographs of parasagittal sections of thoracic spinal cord after labeling the T8 DRG. As the dorsoventral extent of the Ia projection will depend on the mediolateral position of the section, for each animal the section showing the maximum ventral extent of axons was chosen for analysis. Sections from eight animals treated with hrNT-3 and five animals treated with hrBDNF were compared with sections from six age-matched controls. The different groups were compared using one-way ANOVA.

\section{Results}

\section{$N G F$ and $N T-3$ affect DRG neurons of different sizes}

We first sought to verify that our in utero injections of neurotrophins would have demonstrable effects on DRG cells. We therefore assessed the sizes of dorsal root ganglia and of individual DRG neurons in embryos treated with $\mathrm{mNGF}$ and hrN $\mathrm{l}-3$ and in controls treated with saline. The ganglia of $\mathrm{mNGF}$-treated animals were markedly larger than controls, whereas trcatment with hrNT-3 only slightly increased the overall size of the ganglia. High-power photomicrographs from semithin sections revealed that both mNGF and hrNT-3 increased soma crosssectional areas of DRG neurons, but that the two neurotrophins appeared to affect different populations of DRG neurons (Fig. 1). Administration of $\mathrm{mNGF}$ led to an increase in the size of smaller ganglion neurons, thereby eliminating the usual, obvious discrepancy hetween small (short arrows) and large (long arrows) DRG neurons (compare Fig. $1 A, B$ with $C, D$ ). This resulted in the ganglia of mNGF-treated animals having a rather homogeneous appearance (Fig. $1 C, D$ ). In contrast, treatment with hrNT-3 preferentially increased the size of larger DRG neurons and therefore increased rather than decreased the usual size discrepancies present within the ganglion (compare Fig. $1 A, B$ with $E, F$ ).

In order to quantitate the effects of neurotrophins on individual DRG neurons, we examined DRG cells under high power in semithin plastic sections and traced cell soma profiles for size-frequency histograms. Histograms generated from pooled data from all experiments are shown in Figure 2. Histograms from control animals (black bars) at this age showed a range of sizes with the greatest percentage of DRG neurons falling in the $100 \mu \mathrm{m}^{2}$ bin (50-100 $\mu \mathrm{m}^{2}$ size range). As expected, the sizefrequency histogram was shifted to the right toward larger soma areas in mNGF-treated animals (hatched bars). In particular, the smallest class of neurons, less than $50 \mu \mathrm{m}^{2}$, was almost

Figure 3. C5 dorsal root axons in developing funiculi in control and mNGF-treated animals at E16. The Dil-stained dorsal root axons are viewed from the dorsal surface of the spinal cord in whole-mount preparations. $A-D$ are photomicrographs; $E-H$ are camera lucida tracings. Open arrows in $A$ and $B$ denote DRGs. $M$, medial; $L$, lateral. $A$, Low-power view of the C5 projection in the dorsal funiculi from a control embryo. Note a medial band of axons (thick arrows) presumably from proprioceptive and mechanoreceptive DRG neurons that project to the dorsal column nuclei. Asterisk denotes axons occupying more lateral regions that presumably are from other classes of DRG neurons. $B$, In mNGF-treated animals there is a marked increase in the number and length of dorsal root axons that is particularly prominent in the lateral region (asterisk). $C$, Higher-power view of dorsal root axons from an E16 control embryo. Vertical arrows denote the lateral fibers. $D$, The dramatic effects of mNGF on lateral axons 

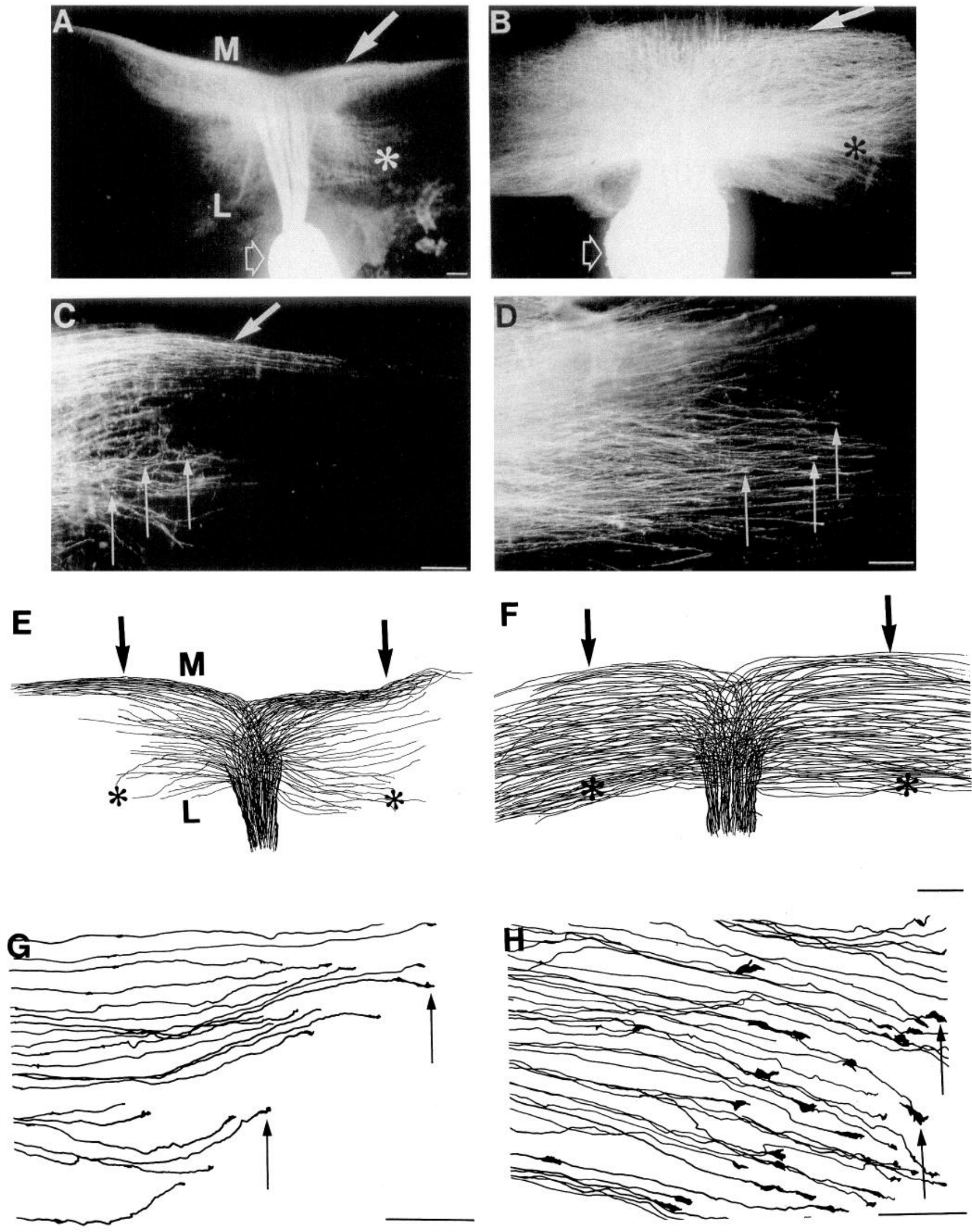

(vertical arrows) are obvious. $E$ and $F$, Camera lucida tracings of DiI-labeled dorsal root axons at E16. The prominent effects of NGF on lateral axons are again apparent. $G$ and $H$, Higher-power camera lucida tracings of $E$ and $F$ in the regions of the asterisks. The presence of growth cones in $G$ and $H$ demonstrates that many of these lateral axons were labeled all the way to their distal tips. The enlarged growth cones in the mNGFtreated animals (arrows) are apparent even at this magnification. Scale bars, $100 \mu \mathrm{m}$. 
Table 1. Axon scores in medial (M) and lateral (L) dorsal funiculi in control and mNGF-treated animals

\begin{tabular}{llllllll} 
& & M1 & M2 & M3 & L1 & L2 & I.3 \\
\hline CTL & 1 & 4 & 3 & 2 & 1 & 0 & 0 \\
& 2 & 4 & 4 & 2 & 2 & 1 & 0 \\
& 3 & 4 & 3 & 2 & 2 & 1 & 0 \\
& 4 & 4 & 3 & 2 & 3 & 0 & 0 \\
NGF & 5 & 3 & 3 & 1 & 4 & 1 & 1 \\
& 1 & 4 & 4 & 4 & 4 & 4 & 3 \\
& 2 & 4 & 4 & 4 & 4 & 3 & 3 \\
& 3 & 4 & 4 & 4 & 4 & 4 & 3 \\
& 4 & 4 & 4 & 4 & 4 & 4 & 3 \\
& 5 & 4 & 4 & 4 & 4 & 3 & 2
\end{tabular}

Axon density was scored on a $0-4$ scale $(4$, axon number $>100 ; 3$, axon number $=50-100 ; 2$, axon number $=25-50 ; 1$, axon number $=5-25 ; 0$, axon number $<$ $5)$. $M$ and $L$ are medial and lateral dorsal funiculi, respectively; $1-3$ denote increasing distance from the $\mathrm{C} 5$ root entry zone.

completely eliminated by mNGF treatment. Also after mNGF treatment, the majority of DRG neurons were in the $150 \mu \mathrm{m}^{2}$ bin (size range 100-150 $\mu \mathrm{m}$ ). Interestingly, however, neurons larger than $150 \mu \mathrm{m}^{2}$ were not increased in frequency in these mNGF-treated animals.

Treatment with hrNT-3 (white bars) resulted in a completely different pattern. There was little change in the frequency of neurons with soma areas less than $50 \mu \mathrm{m}^{2}$. However, neurons with areas between 50 and $150 \mu \mathrm{m}^{2}$ were slightly reduced in frequency compared to controls, whereas neurons between 150 and $200 \mu \mathrm{m}^{2}$ almost doubled in frequency. In addition, more than $16 \%$ of DRG neurons in hrNT-3-treated embryos had soma areas larger than $200 \mu \mathrm{m}^{2}$, as compared to $2 \%$ in controls. In hrNT-3-treated animals, $6 \%$ of DRG neurons had soma areas of greater than $250 \mu \mathrm{m}^{2}$, whereas no DRG neuron in a control population of $1318 \mathrm{DRG}$ neurons was this large at E16.

\section{$m N G F$ stimulates growth of dorsal root axons in developing dorsal funiculi}

We next determined whether mNGF could stimulate growth of dorsal root axons in the dorsomedial and dorsolateral funiculi. For these experiments, mNGF was administered by in utero injection on E14 and E15 and dorsal root axons growing in the funiculi were stained with DiI at E16. E14, which is $48 \mathrm{hr}$ after rat dorsal root axons first enter the spinal cord and bifurcate into rostrocaudally directed branches (I. Silos-Santiago and W. D. Snider, unpublished observations), is probably the first day at which these in utero injections are feasible (L. Zhang, unpublished observations). The normal appearance of the dorsal root projection in the $\mathrm{C} 5$ cervical region at E16 is shown at low power in Figure $3 \mathrm{~A}$ and at higher power in Figure $3 \mathrm{C}$. The spinal cords in these animals were sectioned approximately along the midline and mounted on a slide with the dorsolateral surface up in order to view the growing axons. The photomicrographs show the C5 dorsal root ganglion (open arrow) together with dorsal root axons projecting rostrally and caudally in the spinal cord. In control animals (Fig. 3A,C), a large band of fibers near the midline of the spinal cord (large solid arrows) extends rostrally toward the dorsal column nuclei in the medulla and caudally at least several segments away from the DiI-labeled DRG. These axons are presumably from proprioceptive and mechanoreceptive DRG neurons. The growth cones of the medial axons could not be observed, suggesting that they were not labeled to their farthest rostral extent. Axons occupying more lateral aspects of the dorsal funiculi (Fig. $3 A$, asterisk; $C$, vertical arrows) extended for much shorter distances at this age. Camera lucida tracings of labeled axons from these whole-mount preparations are shown in Figure $3, E$ and $G$. Frequently, growth cones of the most lateral axons (Fig. $3 G$, arrows) could be observed demonstrating that many of these axons are fully labeled at E16.

The appearance of the $\mathrm{C} 5$ dorsal root projection in the $\mathrm{mNGF}$ treated animals is completely different. There was a dramatic increase in the number and length of axons, particularly in the lateral regions (Fig. $3 B, D$ ). Furthermore, it was obvious that growth cones of axons in the lateral region were larger in mNGFtreated animals than in controls (compare Fig. 3, $G$ and $H$ ). Growth cones of lateral fibers in mNGF-treated animals were found to be roughly twice as large as growth cones in control animals (see below). From the anatomical material, it appeared that the effect of NGF was restricted to axons that normally course in the lateral aspect of the dorsal funiculus. However, we cannot exclude the possibility that some medial fibers were also stimulated and crossed over into the lateral region.

In order to quantitate the effects of $\mathrm{mNGF}$ injections on neurite outgrowth of dorsal funiculi, $35 \mathrm{~mm}$ negatives of photomicrographs from five control and five NGF experiments were divided into six regions (for details, see Materials and Methods). Axon outgrowth in dorsal funiculi was scored according to conventional methodology in each of three medial and three lateral areas. The results are shown in Table 1 . In mNGF-treated animals, there was a marked increase in neurite score in the lateral regions and regions farthest away from the dorsal root entry zone. Such increases in neurite score could be due to increases in the length of axons, increases in the numbers of DRG neurons, branching of individual axons, or some combination of all of these. Distinguishing among these possibilities will require staining the axons of individual dorsal root ganglion cells after NGF treatment.

$m N G F$ enhances growth of dorsal root axon collaterals in gray matter

In order to address the question of whether mNGF may influence growth of axon collaterals in spinal gray matter, we studied the dorsal root afferent projection in transverse sections of $\mathrm{C5}$ cervical spinal cord. Three time points (E16, E17, and E19) were examined after double injections of NGF (see Materials and Methods). These time points were chosen because the first collaterals enter gray matter between E14 and E15 in the cervical region (Snider et al., 1992). The results of all three paradigms show that NGF strikingly promoted the growth of collaterals of certain classes of dorsal root axons. Examples of our results at E1 7 and E19 are shown in Figure 4. In NGF-treated animals, axons normally projecting to the superficial dorsal horn were longer and appeared to be more numerous than in controls (compare Fig. 4, $A$ and $B$, asterisks). In addition, aberrant bundles of axons projecting toward and frequently crossing the midline could be observed (Fig. $4 B$, large arrows). Although a few axons cross the midline in control animals (Fig. $4 A$, large arrow) in the $\mathrm{C} 5$ region, this projection was sparse in every control animal examined (see below). Furthermore, in mNGF-treated animals, multiple crossing bundles were frequently observed, which was never the case in controls. Similar phenomena were observed in E19 animals after injections of mNGF at E15 and E1 7 (Fig. $4 C, D$ ). There were no obvious effects on the numbers, 

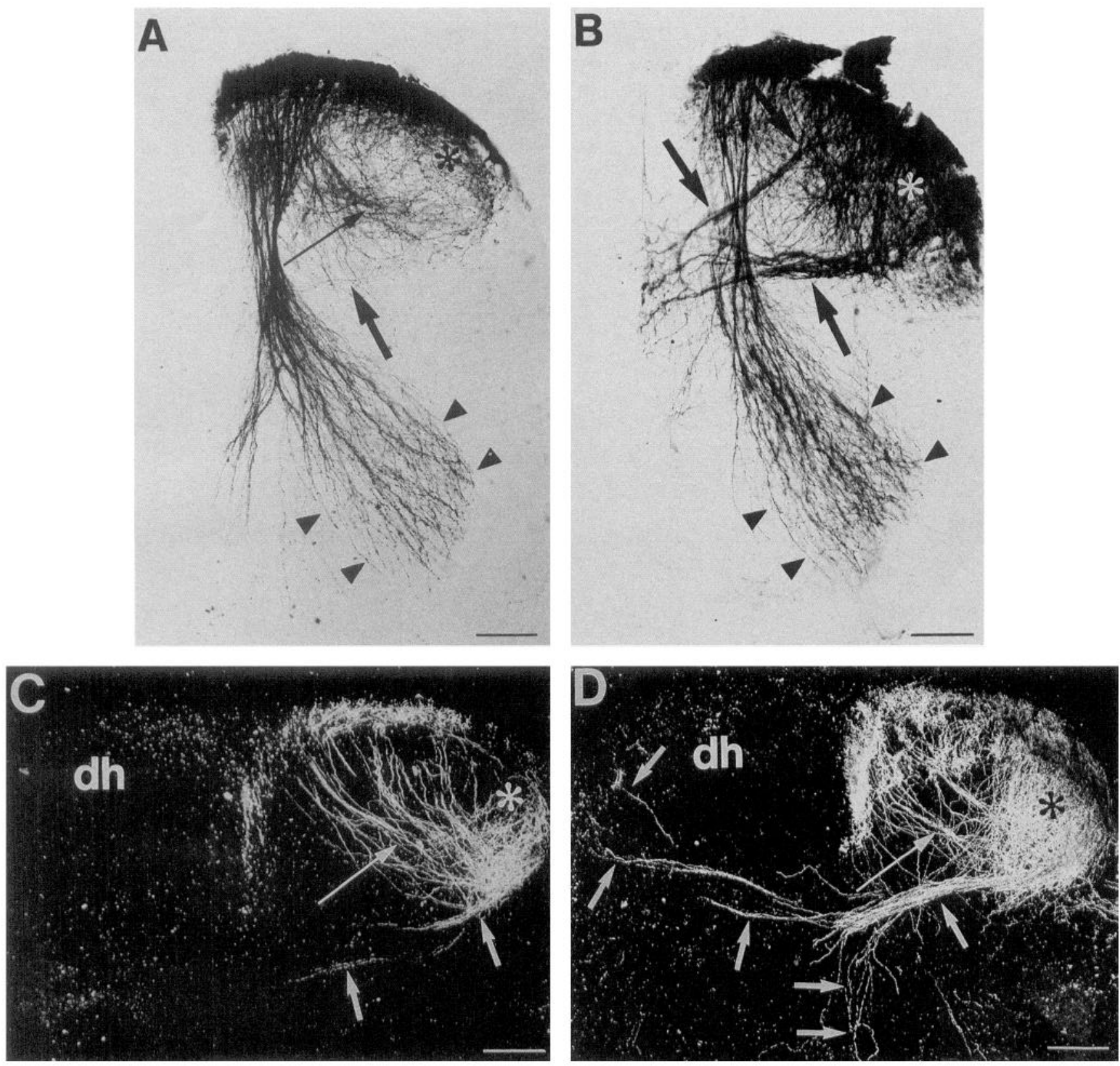

Figure 4. The C5 dorsal root afferent projection in spinal gray matter in control and mNGF-treated animals. $A$ and $C$ are photomicrographs of photoconverted sections from controls at E17 (bright-field) and E19 (dark-field). $B$ and $D$ are from NGF-treated animals. $A$, By E17 the major classes of dorsal root afferents have entered the gray matter of the spinal cord in the C5 region. Ia afferents to the motor pool are depicted by arrowheads. Small-diameter cutaneous afferents entering laterally and projecting to superficial dorsal horn are denoted by asterisk. Axons entering medially and projecting to laminae III and IV (presumably low-threshold mechanoreceptors) are indicated by thin arrow. Only a few axons cross the midline in the C5 region (thick arrow). B, In animals treated with mNGF on E15 and E16, axons entering laterally are markedly stimulated and are longer and more numerous than in controls (asterisk). Many of these axons project toward the midline in thick bundles (arrows). In contrast, Ia afferents are not demonstrably affected (arrowheads). $C$, Dorsal root axons labeled in the C5 segment by placement of Dil crystals in skin at E19. Axons entering laterally and terminating in superficial dorsal horn are denoted by asterisks. Axons entering medially and terminating in laminae III and IV are indicated by the thin arrow. Only the most lateral region of dorsal horn is labeled because crystals were placed on skin along the dorsum of the animal. Again, only a few axons project toward the midline (thick arrows) in this section from a control embryo. $D$, mNGF treatment at E15 and E17 results in marked stimulation of the superficial axons (asterisks) and the formation of axon bundles projecting toward and crossing the midline (thick arrows). A few axons from the crossing bundles grew downward along the midline, a phenomenon never observed in control animals. dh, dorsal horn. Scale bars, $100 \mu \mathrm{m}$.

length, or branching of dorsal root axons projecting to the ventral horn (compare Fig. 4, $A$ and $B$, arrowheads). However, it should be noted that in DiI-stained material it would be difficult to exclude an effect of NGF on the numbers of Ia axons, and this issue will require further study.
The influence of $\mathrm{mNGF}$ on dorsal root axon collateralization at different ages is shown in more detail in the camera lucida tracings of the C5 dorsal root projection in Figure 5. In these drawings, small-caliber axons entering laterally and normally terminating in the superficial dorsal horn are rendered in red. 
A

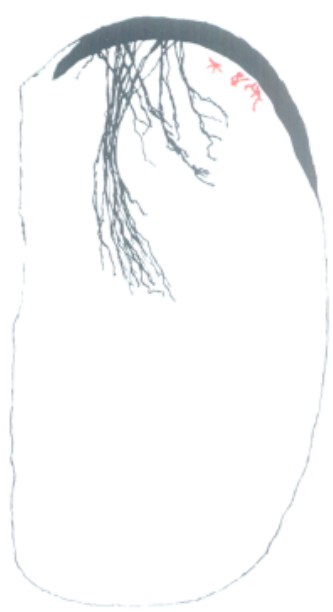

D

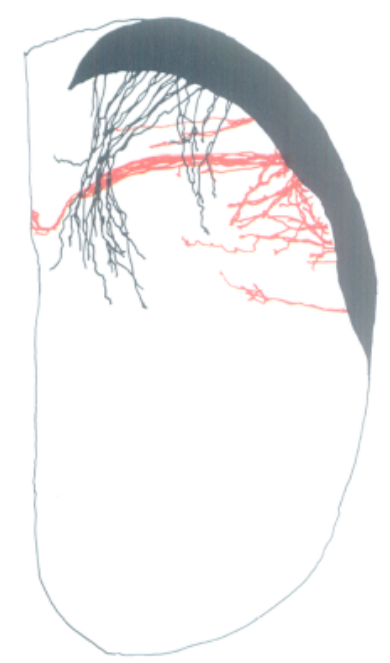

B

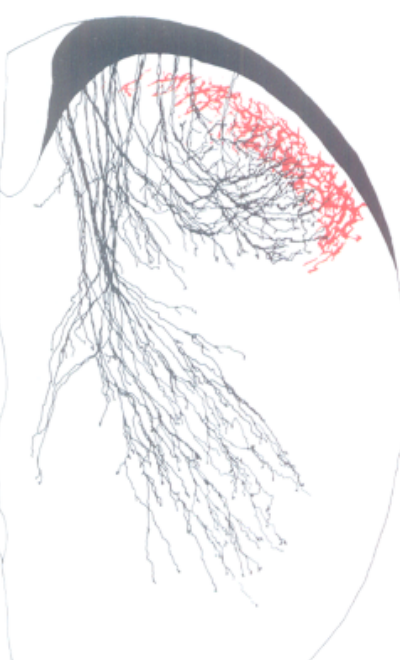

$\mathbf{E}$

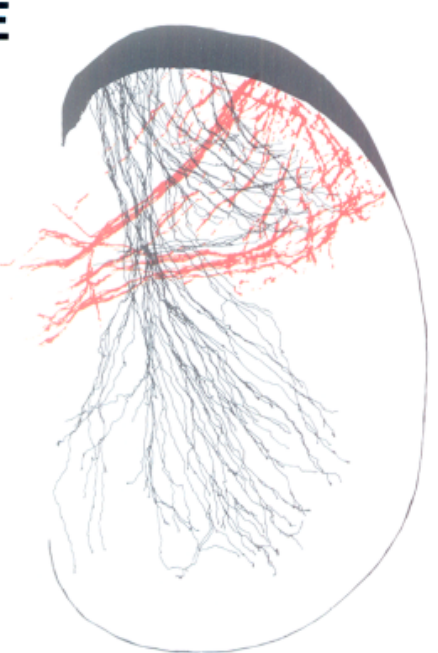

C

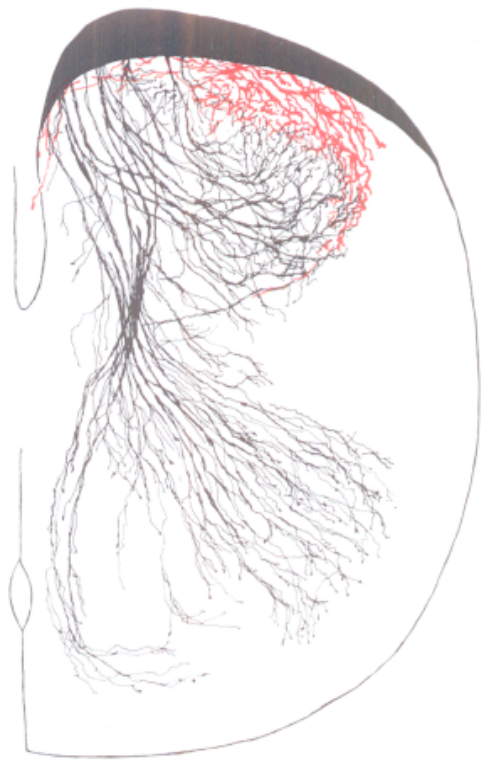

$\mathbf{F}$

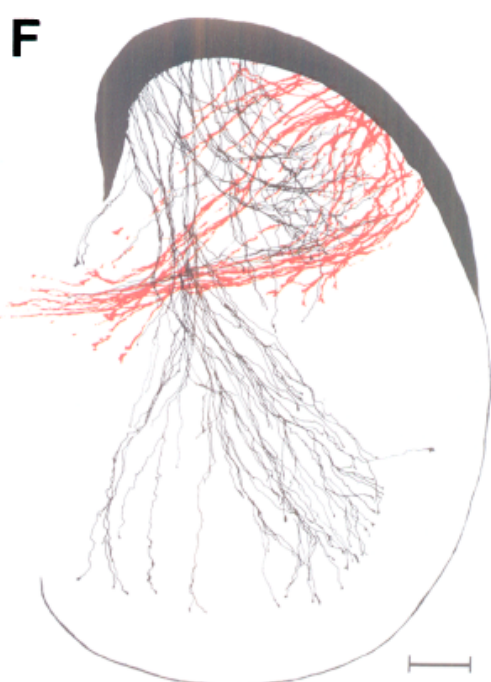

Figure 5. Camera lucida tracings of the $\mathrm{C} 5$ dorsal root afferent projection at different ages in control and mNGF-treated animals. Left, E16; middle, E17; and right, E19. Top, controls; bottom, animals injected with mNGF according to Materials and Methods. Different classes of afferents are rendered in different colors. Ia afferents and afferents entering medially and turning upward (probably hair follicle and other low-threshold mechanoreceptors) are rendered in black. Afferents entering more laterally and occupying the superficial dorsal horn in control animals are rendered in red. Left. Effects of mNGF injections on lateral fibers are readily apparent even at E16 $(D)$. Note that lateral fibers $($ red $)$ are more numerous and longer, but that there is no effect on medial fibers (black). Middle, In comparing $B$ (control) and $E$ (NGF) at E17, it is apparent that the fibers rendered in red are longer than in control animals. Fascicles of such fibers frequently project to the midline and cross to the opposite side of the spinal cord. No effects on Ias or hair follicle afferents (black) were apparent. Right, At E19 the pattern is similar. Axons entering laterally (red) are markedly stimulated by mNGF $(F)$, whereas other classes (black) are not obviously affected. Although a few crossing fibers are present in some segments of $\mathrm{C} 5$ in control animals $(C)$, these are much less numerous than animals treated with mNGF $(F)$. Scale bar, $100 \mu$ m.

Larger-caliber axons entering medially and terminating in ventral laminae of the dorsal horn and ventral horn are rendered in black. Striking effects of NGF on lateral fibers are apparent even at E16, the first day superficial fibers enter the gray matter in controls (compare Fig. 5, $A$ and $D$ ). A marked increase in numbers of axons entering laterally was observed. Most of these projected toward the midline. In contrast, no effects on fibers entering medially were seen. Effects on these medial axons would have been particularly easy to demonstrate if present because the axons projecting to the ventral horn are short and unbranched at this age.

At E17, the projections of all classes of dorsal root axons are more developed in control animals (Fig. 5B). Ia axons have reached the ventral horn and begun to arborize in motor pools. Hair follicle afferents and other low-threshold mechanoreceptors have reached laminae III and IV of the dorsal horn and have turned upward in their characteristic "flame-shaped" appearance. Finally, axons have entered the superficial part of the dorsal horn to terminate laminae I and II. In animals treated with NGF at E15 and E16, growth of superficial axons was greatly stimulated (Fig. $5 E$ ). Such axons were longer and appeared to be more numerous, and there were aberrant bundles projecting toward and crossing the midline. Again, no effects on afferents terminating in the deeper laminae of the dorsal horn 


\begin{tabular}{|c|c|c|c|}
\hline & Ia & $\mathrm{HF}$ & LF \\
\hline CTL & $29 \pm 19$ & $14 \pm 9$ & $17 \pm 11$ \\
\hline$n$ & 118 & 120 & 130 \\
\hline NGF & $29 \pm 18$ & $16 \pm 10$ & $36 \pm 21^{*}$ \\
\hline$n$ & 137 & 116 & 129 \\
\hline
\end{tabular}

Values are means $\pm \mathrm{SD} ; n$, number of growth cones analyzed. Ia, Ia afferants; $\mathrm{HF}$, hair follicle afferents; $\mathrm{LF}$, lateral fibers.

* Value significantly different from controls ( $p<0.001$ by one-way ANOVA).

or the ventral horn were obvious. Although we cannot exclude an effect on the number of such axons (it is very difficult to quantitate axon number in these bulk-labeled preparations), it was not apparent that these fibers were any longer in mNGFtreated than in control animals, or that they projected to aberrant locations. At E19, in control animals, dorsal root axons were longer and terminal arbors are more complex (Fig. $5 C$ ). The effects of treatment with NGF (Fig. $5 F$ ) are similar to those observed at younger ages.

It is important to emphasize that the situation with regard to fascicles that cross the midline is complex because in axial (e.g., thoracic) regions of spinal cord there is a substantial projection of crossing axons in normal animals. The increase in numbers of fascicles crossing the midline in mNGF-treated animals was particularly apparent in parasagittal sections that included multiple spinal cord segments. Such sections clearly revealed the massive increase in the number of crossing axons in the NGFtreated animals even in thoracic spinal cord (data not shown).

A final observation of interest is that, to some extent, normal spatial cues that constrain the dorsal root projection were maintained in mNGF-treated animals. The exuberant projections grew toward and frequently crossed the midline to project to the contralateral dorsal horn. As was the case in control animals, virtually no axons that entered the gray matter laterally extended ventrally to reach the ventral horn. Thus, administration of mNGF did not completely override the normal spatial cues that restrict different populations of afferent axons to different regions of the spinal gray matter.

\section{Selective influences of NGF on different classes of dorsal root afferents}

It was apparent in all of these preparations that NGF had marked influences on growth cones of certain classes of axons in spinal gray matter. In order to quantitate this effect, we traced the growth cones of axons that could be assigned to a specific class by the position of entry into the spinal gray matter and the location of the terminal field. For example, gruwth cones of Ia afferents could be confidently identified because of their location in the ventral horn. Growth cones of other axons could be tentatively identified as hair follicle afferents because the axons entered the spinal gray medially, projected ventrally to laminae IV and V, and then turned upward to terminate in lamina III. Finally, axons that entered the gray matter in the lateral region of the dorsal horn had either a straight or circumferential trajectory and possessed growth cones that were found in laminae I and II in control animals. Growth cones were studied in E17 animals that had been treated with NGF twice on E1 5 and E16.

It is apparent that NGF had striking effects on growth cones of some classes of afferents, but not on others. Growth cones of
Table 3. Length of Ia fascicles in gray matter at E16 $(\mu \mathrm{m})$

\begin{tabular}{lclc} 
& CTL & NT-3 & BDNF \\
\hline$n$ & 61 & 80 & 51 \\
Mean & $159 \pm 25$ & $70 \pm 13^{*}$ & $151 \pm 17$
\end{tabular}

$n$, number of Ia fascicles measured. Values given are the mean $\pm \mathrm{SD}$. The mean dorsoventral extent of the spinal cord at E16 was $286 \mu \mathrm{m}$ in controls and was not significantly different in animals treated with neurotrophins.

* Significantly different from control ( $p<0.001$ by one-way ANOVA).

lateral fibers were markedly stimulated by NGF (Fig. $3 H$ ). Growth cones of these axons exhibited twice the surface area in mNGF-treated animals as in controls (compare Fig. $3 G, H$, and Table 2). In contrast, there were no demonstrable effects of NGF on other classes of axons. For example, there were no effects of NGF on the growth cones of Ia afferents or the growth cones of hair follicle afferents.

\section{hrNT-3 inhibits growth of dorsal root axons in gray matter at early developmental stages}

In order to determine whether these effects of NGF on axon growth and branching generalized to other neurotrophins, influences of BDNF and NT-3 were examined in these same paradigms. It has been hypothesized that NT-3 is a growth factor for proprioceptive DRG neurons, including the Ia muscle affcrents that project to the ventral horn (see below). In order to assess the effects of neurotrophins on Ia afferent axons, we studied all fascicles of axons projecting toward the ventral horn in parasagittal sections of spinal cord after labeling the T8 DRG. Preparations were examined at E1 6 because it is straightforward to determine the maximum ventral extent of dorsal root axon growth at this early stage. Neurotrophins were administered at E14 and E15. It is important to note that at E14, Ia axons have not yet penetrated spinal gray matter (Snider et al., 1992). Figure 6 shows midthoracic spinal cords from these preparations at $4 \times$ (left panels) and $10 \times$ (right panels) magnifications. The ventral edge of the cord is denoted by dashed lines in the left panels. Arrows on the right denote the maximum ventral extent of fascicles of Ia axons. In control animals at E16 (Fig. 6A, $B$; Table 3), Ia axons have projected more than halfway to the motor pools in the ventral region. In animals treated with hrBDNF at E14 and E15 (Fig. 6C,D; Table 3), we see neither an increase nor a decrease compared to controls in the ventral extent of this projection.

Treatment with hrNT-3 (Fig. $6 E, F$ ) produced very clear-cut and surprising results. In each of seven animals examined in three separate litters, treatment with hrNT-3 resulted in inhibition of axon growth in gray matter. Thus, Ia axons projecting to ventral horn had grown only $25 \%$ of the way along the dorsoventral axis by E16 in hrNT-3-treated animals. The magnitude of this effect was quantitated and the results of all experiments are shown in Table 3. Observations in the transverse plane from the lumbar region of the spinal cord at E16 confirmed this inhibitory effect (Fig. $7 A, B$ ). It is important to emphasize that this inhibitory effect on axon growth in gray matter is not inconsistent with the fact that hrNT-3 may influence DRG neuron survival or increase cell size (Hory-Lee et al., 1993; see above). No judgement could be made about the numbers of fascicles or individual axons that could have been increased in animals treated with neurotrophins, but could not be measured accurately with these methods. 

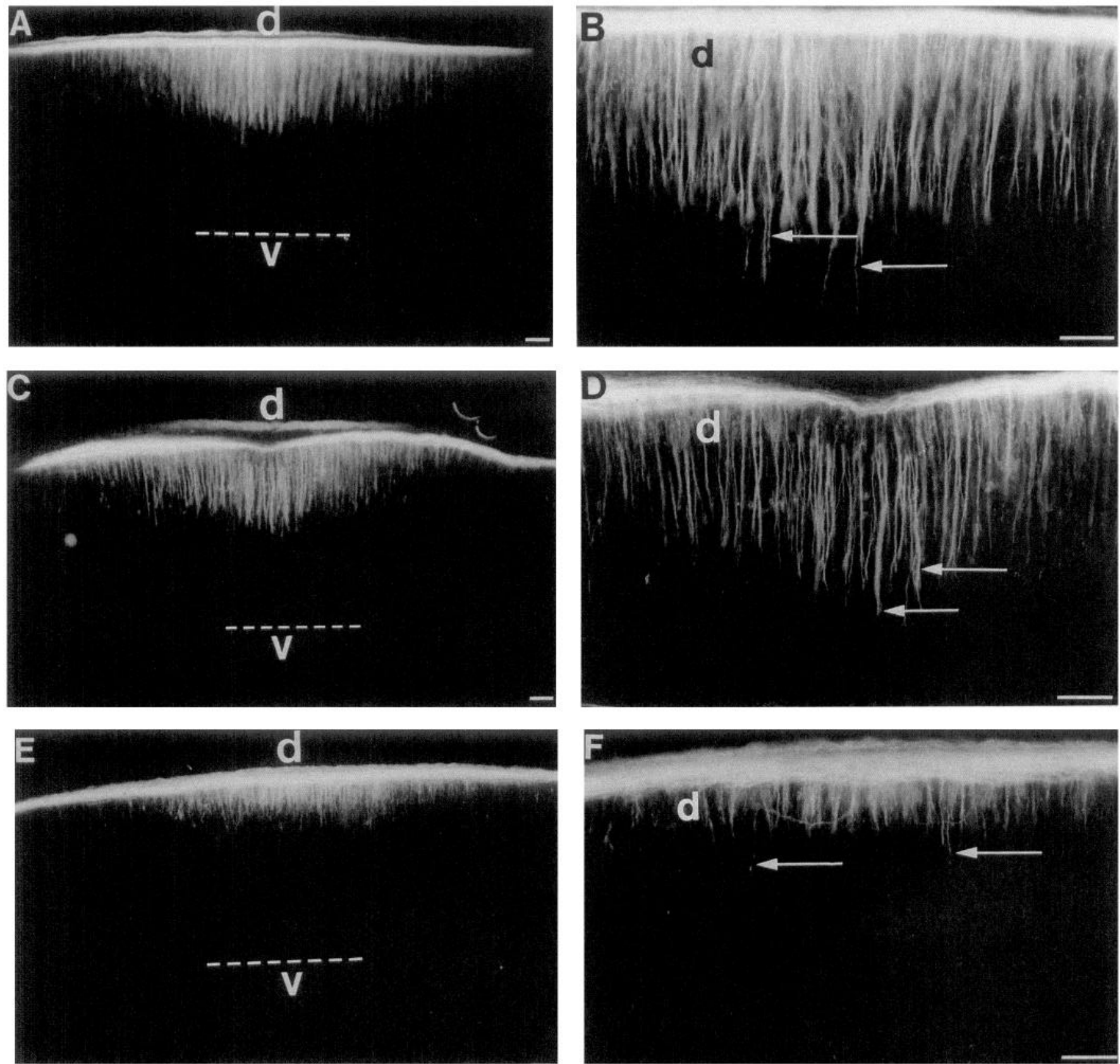

Figure 6. Influences of neurotrophins on dorsal root axon growth in gray matter at early developmental stages. Panels show low-power (left) and higher-power (right) photomicrographs of parasagittal sections of midthoracic spinal cord at E16 in control and neurotrophin-treated embryos. Animals were treated on E14 and E15. $A$ and $B$, Control. $C$ and $D$, hrBDNF treated. $E$ and $F$, hrNT-3 treated. In all preparations the left T8 DRG was labeled with DiI. Dorsal root axon collaterals project toward, but have not reached, the ventral horn at this age. The ventral edge of the spinal cord is denoted by dashed lines in the left panels. In the right panels, arrows denote the maximum ventral extension of dorsal root axon collaterals. In comparison with control $(A, B)$ and hrBDNF-treated animals $(C, D)$, axon growth in gray matter was clearly inhibited in animals treated with hrNT-3 $(E, F)$. Scale bars, $100 \mu \mathrm{m}$.

The effects of hrBDNF and hrNT-3 were also examined in older animals. Embryos were treated at E15 and E17 and examined at E19. Figure 7, $C$ and $D$, shows photomicrographs of transverse sections through the middle of the C5 spinal segment after labeling the C5 DRG with DiI at E19. No clear-cut differences in the dorsal root projection between control $(C)$ and hrNT-3-treated animals $(D)$ are apparent. In particular, in hrNT3-treated animals $(C)$, Ia axons were not longer, did not project into inappropriate regions, and did not appear to be excessively branched. Results for hrBDNF treatment were similar (data not shown). In a few preparations we determined the area of growth cones of Ia axons in NT-3-treated animals. Ia axons from NT3 -treated animals had an area of $25.4 \mu \mathrm{m}^{2}(n=170)$ versus 24.0 $\mu \mathrm{m}^{2}(n=189)$ for controls.

It is important to stress that minor differences in the dorsal root projections between control and neurotrophin-treated animals could have been missed. For example, if hrNT-3 influences survival of some DRG neurons, one may expect to see increased numbers of Ia axons. There was no accurate way to quantitate the number of fascicles or number of axons per fas- 

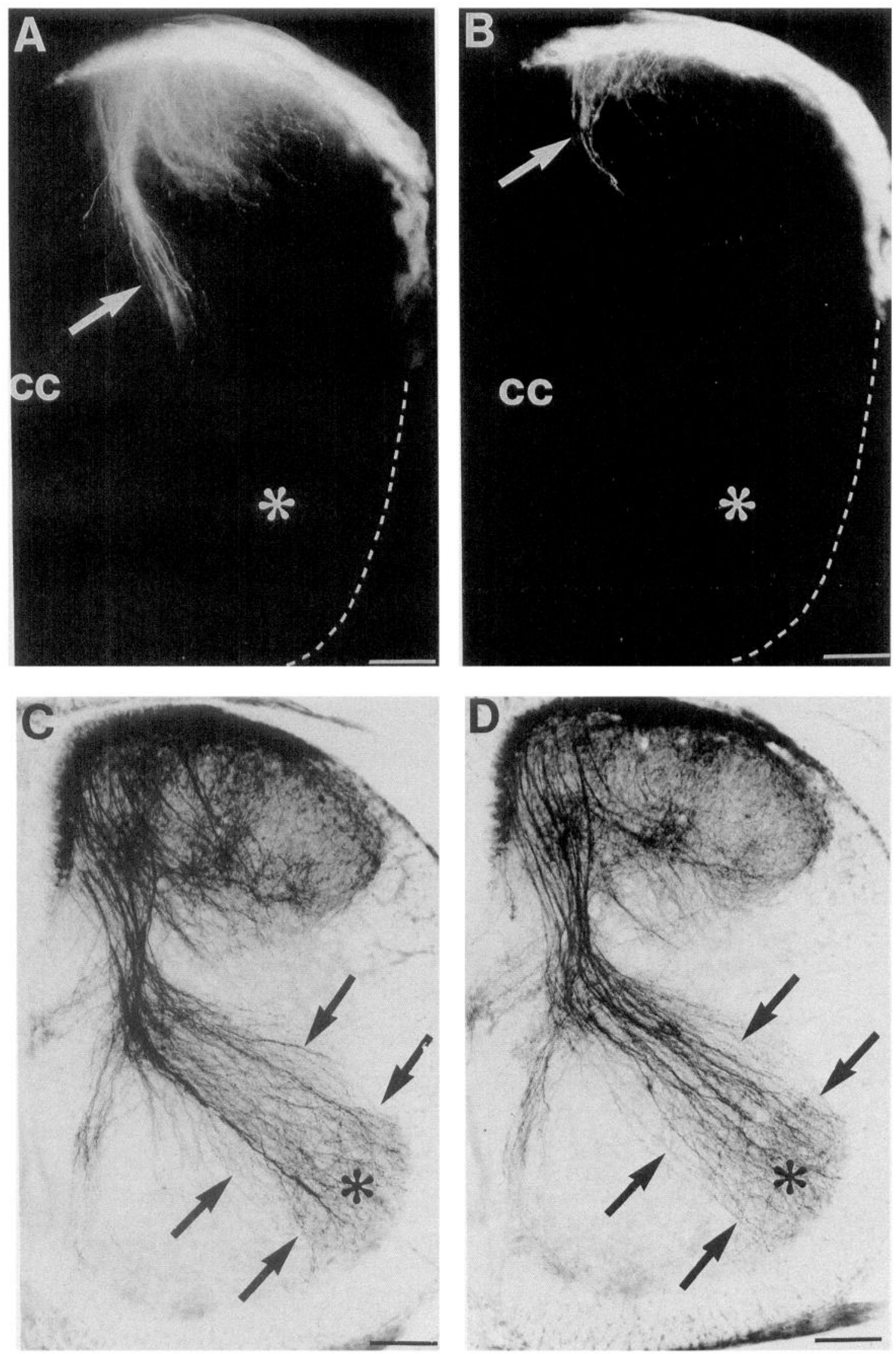

Figure 7. Dorsal root afferent projection in transverse sections in control and NT-3-treated animals. Left, Control. Right, hrNT-3 treated. A and $B$, E16. Arrows show Ia afferents in the L4 spinal segment. Asterisks indicate motor pool. Note that in embryos treated with hrNT-3, only a few axons have penetrated the spinal gray. Outline of spinal cord is denoted by dashed lines. $C$ and $D$, E19, C5 cervical region. When hrNT-3 is administered to older animals there is no clear-cut effect on the length or branching of Ia axons (arrows). Asterisks indicate the motor pools. Scale bar, $100 \mu \mathrm{m}$. 
cicle in this material. Furthermore, effects on subtle parameters such as terminal branching would not have been demonstrated using these techniques.

Interestingly, inhibitory effects of hrNT-3 were no longer apparent in these older animals. However, these animals were given their first treatment at E15, a stage at which Ia axons have already penetrated the gray matter of the spinal cord. In order to pursue this issue further, in four animals, treatment was begun at E14. Even in these animals, some Ia axons were visualized in the ventral horn by E17, suggesting that inhibitory effects do not result in permanent changes in organization of the dorsal root projection (data not shown).

\section{Discussion}

$N G F$ regulates rate of axon growth

An essential finding of this study is that exogenous mNGF enhances dorsal root axon growth in spinal axon tracts and gray matter in vivo. Thus, at early stages, some classes of dorsal root axons extend roughly twice as far in white matter as controls. Growth of dorsal root axon collaterals in gray matter is also enhanced. The fact that axons have extended farther over a given time period suggests that NGF regulates the rate of axon growth in the spinal cord. It is also probable that NGF influences the number of dorsal root axons in the funiculi via effects on DRG neuron survival and axon branching (see Erzurumlu et al., 1992; Li et al., 1993). We could not be confident about effects on axon number using the bulk-labeling methods employed in this study.

The increase in rate of axon growth observed here obviously parallels the well-established effects of NGF on neurite outgrowth from DRG explants in vitro. Indeed, the scoring system we employed to quantitate axon growth was derived from similar systems used in vitro that score neurite outgrowth as a bioassay for NGF. NGF-induced axon growth in vitro is associated with upregulation of mRNA for microtubule associated proteins (MAPs), as well as phosphorylation of MAPs, effects that are thought to increase tubulin polymerization (Drubin et al., 1985, 1988; Aletta et al., 1989). Although no evidence as yet speaks to the role of MAPs or other cytoskeletal elements in regulating growth factor actions on axon elongation during development in vivo, it will be straightforward to address this issue using standard techniques to quantitate gene expression in NGF-treated embryos.

What are the functions of this regulation of rate of axon growth by NGF in vivo? An important implication of this finding is that growth factors are part of complex regulatory mechanisms that cause or allow axons to arrive in target fields at appropriate times in relation to the onset of synaptogenesis. Obviously, the timing of axon branching into target fields must be coordinated with the synthesis of synapse-specific molecules by postsynaptic cclls. Arrival of axons too carly or too latc in the target field may disrupt normal connectivity (Goodman and Shatz, 1993). Interestingly, for DRG neurons, this regulation of rate of axon growth in spinal cord is probably in response to peripheral target-derived NGF. Thus, some DRG neurons express NGF receptors and presumably have access to peripheral sources of NGF by E13, which is well before they branch into gray matter of the spinal cord (for data on NGF mRNA synthesis in developing mouse, see Davies et al., 1987; Schecterson and Bothwell, 1992; see also Snider et al., 1992; Mu et al., 1993). It remains unclear whether NGF may also be synthesized in spinal cord at early developmental stages. Whether rate of growth of axons in other developing CNS pathways may also be regulated by growth factors is unknown, but this issue can be studied using approaches similar to the one outlined here.

A final important point with regard to NGF effects on dorsal root axons is that NGF action did not completely override normal spatial cues. Thus, NGF-stimulated axons almost invariably remained in the dorsal horn. Even when massive growth of axon bundles was stimulated, axons grew contralaterally to the dorsal horn on the opposite side of the spinal cord and never into the ventral horn. A logical interpretation of this finding is that surface molecules normally constrain the growth of DRG axons to certain regions of the spinal cord and that the actions of these molecules are not completely overridden by increasing the available supply of NGF.

\section{Enhancement of axon growth by NGF is selective}

A clear-cut conclusion from the present findings is that regulatory influences of NGF on dorsal root axon growth are strikingly selective. It was readily apparent that axons stimulated by NGF were restricted to the dorsal horn, whereas axons projecting to the ventral horn did not respond. Furthermore, it was straightforward using our approach to show that growth cones of certain classes of dorsal root afferents were markedly enlarged, while those of other classes were not.

Almost certainly this striking selectivity is associated with expression of the $t r k A$ proto-oncogene by a subclass of DRG neurons. It is now clear that the trk family of receptor tyrosine kinases mediates the biological actions of ncurotrophins cither independently or in association with p75 (Klein et al., 1989, 1990, 1991; Martin-Zanca et al., 1990; Cordon-Cardo et al., 1991; Lamballe et al., 1991; Soppet et al., 1991). mRNA for trkA, the NGF high-affinity receptor, is expressed in DRGs from an early stage of development, at least by $\mathrm{E} 12$, and thus trkA could clearly mediate the effects observed in the experiments carried out here (Ernfors et al., 1992; Schecterson and Bothwell, 1992; Mu et al., 1993). Furthermore, trkA is expressed only in a subset of DRG neurons. Size-frequency histograms show that trkA is expressed by DRG neurons with soma areas at the smaller end of the spectrum (Mu et al., 1993). This latter finding is consistent with our observations that $\mathrm{mNGF}$ stimulates fibers that enter laterally and normally terminate in the superficial dorsal horn. We suggest that mNGF regulates rate of growth of dorsal root axons but does so only for those that express the appropriate receptor tyrosine kinase, $t r k \mathrm{~A}$.

It is important to point out that not all previous experiments are consistent with the idea that effects of exogenous NGF on DRG neurons are selective. For example, in chick, NGF saves both "large" ventrolateral and "small" dorsomedial DRG neurons from naturally occurring cell death (Hamburger et al., 1981). Some experiments assessing effects of NGF on cell death after axotomy in the neonatal period have suggested that NGF saves virtually all cells that die in this setting (see Johnson et al., 1986, for a review). Furthermore, one study showed clear-cut effects on synaptic transmission of Ia afferents in neonatal rats, and another study showed effects on muscle spindles, the peripheral receptors of Ia afferents (Miyata et al., 1986; Sekiya et al., 1986). Finally, it has been reported that NGF is effective in preventing deleterious effects of cis platinum neuropathy, a neuropathy thought to influence primarily large, proprioceptive DRG axons (Apfel et al., 1992).

It is interesting to consider why NGF apparently has effects on a variety of DRG cell classes in these latter experimental paradigms, and whether the results presented here are in conflict 
with these findings. In axotomy paradigms, it is possible that DRG neurons that do not normally express $t r k$ A may do so after axotomy, thus allowing them to respond to NGF. This issue is currently under active investigation (Tetzlaff et al., 1992). A second issue to consider is that NGF may stimulate local production of neurotrophins within the DRG. It has recently been established that mRNAs for other neurotrophins, BDNF, and probably NT-3 are localized to DRG neurons (Ernfors and Persson, 1991; Schecterson and Bothwell, 1992). If these DRG neurons express trkA, then administration of exogenous NGF should stimulate production of BDNF and NT-3 within the DRG. This may lead to increased survival of other DRG cell classes (although not necessarily increases in neurite outgrowth; see below). Determining whether mRNA for other neurotrophins is stimulated after NGF administration, and whether trkA and BDNF or NT-3 expression are colocalized should be straightforward and should ultimately allow resolution of these seemingly contradictory findings.

\section{Inhibition of dorsal root axon growth by NT-3}

A surprising and striking result of this study is that we were unable to generalize the effects of mNGF on dorsal root axon growth to other neurotrophins. Thus, hrBDNF had no clear-cut effects and hrNT-3 had a surprising inhibitory effect on axon growth at early developmental stages. In interpreting these findings, it is important to examine potential limitations of our experimental paradigms. One cxplanation for the lack of stimulation of DRG axon growth in our experiments would be lack of appropriate biological activity of the human recombinant neurotrophins. Strongly against the idea that human recombinant factors are inactive is the finding of increased DRG neuron soma areas in animals treated with hrNT-3. Size-frequency histograms of DRG neurons showed a clear-cut shift to larger soma areas in a completely different pattern than that observed after treatment with $\mathrm{mNGF}$. A particularly striking finding was that after hrNT-3 treatment, we encountered DRG neurons with soma areas larger than any encountered in control populations. The finding that NT-3 preferentially influences large cells is consistent with the fact that $t r k \mathrm{C}$ is preferentially expressed by large DRG neurons and that NT-3 supports DRG neurons in vitro that have been retrogradely labeled from muscle (HoryLee et al., 1993; Mu et al., 1993). That NT-3 is a physiologically relevant growth factor for large proprioceptive DRG neurons has recently been proven by the finding that la axons projecting to the ventral horn are absent in animals where $t r k \mathrm{C}$ has been deleted by homologous recombination (Klein et al., in press).

There are at least two important reasons why hrNT-3 may have inhibitory actions on DRG axon outgrowth in vivo. An interesting possible explanation is related to the widespread expression of the high-affinity NT-3 receptor trkC, by supporting satellite and Schwann cells in the DRG, and by virtually all neurons and many glial cells in the spinal cord (Carroll et al., 1992; Ernfors et al., 1992; Mu et al., 1993; Yan et al., 1993). This pattern stands in contrast to the strikingly restricted expression of the high-affinity NGF receptor, trkA (Carroll et al., 1992; Ernfors et al., 1992; Mu et al., 1993; Yan et al., 1993). Many of these trkC receptors, particularly those on Schwann cells and glial cells, are isoforms that lack the tyrosine kinase domain (Klein et al., 1990; Middlemas et al., 1991; Lamballe et al., 1993; Tsoulfas et al., 1993). Although the function subserved by these noncatalytic isoforms is unknown, it has been hypothesized that their expression by Schwann cells and glia may influence axon growth in the setting of development and regeneration (Beck et al., 1993; Frisen et al., 1993). Whatever the function of these noncatalytic receptors, it seems plausible that widespread, high-affinity binding of NT-3 along the pathways of NT-3-responsive dorsal root axons may influence their growth and branching.

It is important to emphasize that these results do not exclude a chemotropic role for NT-3 in attracting axons to their appropriate central target fields (motor pools, dorsal column nuclei). Experiments in vitro utilizing compartmentalized cultures show that phosphorylation of trk and neurite elongation may be regulated by factors applied in the compartment containing neurites, whereas the same factors applied to the compartment containing the cell somata are ineffective (Senger and Campenot, 1993). Indeed, motor neurons express NT-3 mRNA well prior to the arrival of Ia axons in motor pools, consistent with a role for NT-3 in attracting Ia axons to their central target fields. Furthermore, injection of NT-3 (but not BDNF) in spinal cord causes sprouting of axons of corticospinal neurons that are known to express trkC (Schnell et al., 1994). If NT-3 indeed functions as a chemotropic factor, then systemic injections of the factor may disrupt the concentration gradients between developing white and gray matter necessary for the factor to attract growing axons. In support of this idea is a recent study where NGF was overexpressed in SCG cells in transgenic animals and branching into peripheral target fields was inhibited (Hoyle et al., 1993).

Finally, it is important to point out that NT-3 may enhance survival and cell size, but not axon growth. It is increasingly apparent that the NGF-sympathetic ganglion cell model where NGF regulates almost all aspects of ganglion cell biology does not generalize to other neuronal types. Thus, there are numerous examples of situations where a factor regulates survival but not synthesis of transmitter enzymes (Hagg et al., 1992; Yan et al., 1993). It is entirely possible that NT-3 does not regulate gene expression for molecules (e.g., tubulin, MAPs, or GAP43) important for growth cone or axon extension. These mediators of axon growth could be regulated by other growth factors or surface molecules in trkC-expressing neurons. Whether or not NT-3 does regulate gene expression for cytoskeletal elements should be readily testable both in vitro and in vivo.

\section{Note added in proof}

It has recently been demonstrated that NT- 3 does in fact regulate $\mathrm{T} \alpha_{1}$-tubulin and GAP-43 gene expression in injured rubrospinal neurons (W. Tetzlaff, personal communication).

\section{References}

Aletta JM, Shelanski ML, Greene L (1989) Phosphorylation of the peripherin $58-\mathrm{KDa}$ neuronal intermediate filament protein. $\mathrm{J}$ Biol Chem 264:4619-4627.

Apfel SC, Lipton RB, Arrezo JC, Kessler JA (1992) Nerve growth factor prevents experimental cisplatin neuropathy. Ann Neurol 31: 76-80.

Beck KD, Lamballe F, Klein R, Barbacid M, Schauwecker PE, McNeill TH, Finch CE, Hefti F, Day JR (1993) Induction of noncatalytic trkB neurotrophin receptors during axonal sprouting in the adult hippocampus. J Neurosci 13:4001-4014.

Berkemeier LR, Winslow JW, Kaplan DR, Nikolics K, Goeddel DV, Rosenthal A (1991) Neurotrophin-5: a novel neurotrophic factor that activates trk and trkB. Neuron 7:857-866.

Bocchini V, Angeletti PU (1969) Nerve growth factor purificationa 30,000-molecular weight protein. Proc Natl Acad Sci USA 64:787794.

Bolz J, Novak N, Gotz M, Bonhoeffe T (1990) Formation of target- 
specific neuronal projections in organotypic slice cultures from rat visual cortex. Nature 346:359-362.

Carroll SL, Silos-Santiago I, Frese SE, Ruit KG, Milbrandt J, Snider WD (1992) Dorsal root ganglia neurons expressing trk are selectively sensitive to NGF deprivation in utero. Neuron 9:779-788.

Cordón-Cardo C, Tapley P, Jing S, Nanduri V, O'Rourke E, Lamballe F, Kovary K, Klein R, Jones KR, Reichardt LF, Barbacid M (1991) The $t r k$ tyrosine protein kinase mediates the mitogenic properties of nerve growth factor and neurotrophin-3. Cell 66:173-183.

Davies AM, Thoenen H, Barde YA (1986) The response of chick sensory neurons to brain-derived neurotrophic factor. J Neurosci 6:1897-1904.

Davies AM, Bandtlow C, Heumann R, Korsching S, Rohrer H, Thoenen $\mathrm{H}$ (1987) Timing and site of nerve growth factor synthesis in developing skin in relation to innervation and expression of the receptor. Nature 326:353-358.

Drubin DG, Feinstein SC, Shooter EM, Kirschner MW (1985) Nerve growth factor-induced neurite outgrowth in PC12 cells involved the coordinate induction of microtubule assembly and assembly-promoting factors. J Cell Biol 101:1799-1807.

Drubin DG, Kobayashi S, Kellogg D, Kirschner MW (1988) Regulation of microtubule protein levels during cellular morphogenesis in nerve growth factor-treated PC12 cells. J Cell Biol 106:1583-1591.

Ernfors P, Persson H (1991) Developmentally regulated expression of HDNF/NT-3 mRNA in rat spinal cord motoneurons and expression of BDNF mRNA in embryonic dorsal root ganglion. Eur $J$ Neurosci 3:953-961.

Ernfors P, Merlio JP, Persson H (1992) Cells expressing mRNA for neurotrophins and their receptors during embryonic rat development. Eur J Neurosci 4:1140-1158.

Erzurumlu R, Takahashi H, Jhaveri S, Mckay R (1992) Trigeminal ganglion outgrowth in organotypic co-cultures. Soc Neurosci Abstr 18:220.

Frisen J, Valerie MKV, Fried K, Risling M, Persson H, Trotter J, Hokfelt T, Lindholm D (1993) Characterization of glial trkB receptors: differential response to injury in the central and peripheral nervous systems. Proc Natl Acad Sci USA 90:4971-4975.

Godement P, Vanselow J, Thanos S, Bonhoeffer F (1987) A study in developing visual systems with a new method of staining neurons and their processes in fixed tissues. Development 101:697-713.

Gocdert M, Otten U, Hunt SP, Bond A, Chapmen D, Schlumpt M, Lichtensteiger W (1984) Biochemical and anatomical effects of antibodies against nerve growth factors on developing rat sensory ganglia. Proc Natl Acad Sci USA 81:1580-1584.

Goodman CS, Shatz CJ (1993) Developmental mechanisms that generate precise patterns of neuronal connectivity. Cell 72:77-98.

Gunderson RW, Barrett JN (1979) Neuronal chemotaxis: chick dorsal root axons turn toward high concentrations of nerve growth factor. Science 206:1079-1080.

Hagg T, Vahlsing HL, Manthorpe M, Varon S (1990) Nerve growth factor infusion into the denervated adult rat hippocampal formation promotes its cholinergic reinnervation. J Neurosci 10:3087-3092.

Hamburger V, Brunso-Bechtold JK, Yip JW (1981) Neuronal death in the spinal ganglia of the chick embryo and its reduction by nerve growth factor. J Neurosci 1:60-71.

Heffner CD, Lumsden AGS, O'Leary DDM (1990) Target control of collateral extension and directional axon growth in the mammalian brain. Science 274:217-220.

Hohn A, Leibrock J, Bailey K, Barde YA (1990) Identification and characterization of a novel member of the nerve growth factor/brain derived neurotrophic factor family. Nature 344:339-341.

Honig MG, Hume MI (1986) Fluorescent carbocyanine dyes allow living neurons of identified origin to be studied in long term cultures. J Cell Biol 103:171-178.

Hory-Lee F, Russell M, Lindsay RM, Frank E (1993) Neurotrophin-3 supports the survival of developing muscle-sensory neurons in culture. Proc Natl Acad Sci USA 90:2613-2617.

Hoyle GW, Mercer EH, Palmiter RD, Brinster RL (1993) Expression of NGF in sympathetic neurons leads to excessive axon outgrowth from ganglia but decreased terminal innervation within tissues. Neuron 10:1019-1034.

Johnson EM Jr, Rich KM, Yip HK (1986) The role of NGF in sensory neurons in vivo. Trends Neurosci 9:33-37.

Johnson EM Jr, Osborne PA, Taniuchi M (1989) Destruction of sympathetic and sensory neurons in the developing rats by a monoclonal antibody against the nerve growth factor (NGF) receptor. Brain Res 478:166-170.

Kawaja MD, Rosenberg MB, Yohada K, Gage FH (1992) Somatic gene transfer of nerve growth factor promotes the survival of axotomized septal neurons and the regeneration of their axons in adult rats. J Neurosci 12:2849-2864.

Kessler JA, Black IB (1980) Nerve growth factor stimulates the development of substance $P$ in sensory ganglia. Proc Natl Acad Sci USA 77:649-652.

Klein R, Parada LF, Coulier F, Barbacid M (1989) trkB, a novel tyrosine protein kinase receptor expressed during mouse neural development. EMBO J 8:3701-3709.

Klcin R, Conway D, Parada LF, Barbacid M (1990) The $t r k$ B tyrosine kinase gene codes for a second neurogenic receptor that lacks the catalytic kinase domain. Cell 61:647-656.

Klein R, Jing S, Nanduri V, O'Rourke E, Barbacid M (1991) The trk proto-oncogene encodes a receptor for nerve growth factor. Cell 65 : 189-197.

Klein R, Silo-Santiago I, Smeyne RJ, Lira S, Brambrilla R, Bryant S, Zhang L, Snider WD, Barbacid M (1994) Targeted disruption of trkC, the neurotrophin-3 receptor gene, eliminates Ia muscle afferents and results in loss of proprioception. Nature 368:249-251.

Korsching S, Thoenen H (1983) Nerve growth factor in sympathetic ganglia and corresponding target organs of the rat: correlation with density of sympathetic innervation. Proc Natl Acad Sci USA 80: 3513-3516.

Lamballe F, Klein R, Barbacid M (1991) trkC, a new nember of the trk family of tyrosine protein kinases, is a receptor for neurotrophin3. Cell 66:967-979.

Lamballe F, Yapley P, Barbacid M (1993) trkC encodes multiple neurotrophin-3 receptors with distinct biological properties and substrate specificities. EMBO J 12:3083-3094.

Leibrock J, Lottspeich F, Hohn A, Hofer M, Hengerer B, Masiakowski P, Thoenen H, Barde YA (1989) Molecular cloning and expression of brain-derived neurotrophic factor. Nature 341:149-152.

Levi-Montalcini R, Angeletti PU (1968) Nerve growth factor. Physiol Rev 48:534-569.

Levi-Montalcini R, Hamburger V (1951) Selective growth- stimulating effects of mouse sarcoma on the sensory and sympathetic nervous system of the chick embryo. J Exp Zool 116:321-361.

Li L, Oppcnhcim RW, Lei L, Houenou LJ (1993) Neurotrophic factors rescue mouse motoneurons from naturally occurring and axotomy induced cell death. Soc Neurosci Abstr 19:1099.

Lindsay RM, Thoener H, Barde YA (1985) Placode and neural crestderived sensory neurons are responsive at early developmental stages to brain-derived neurotrophic factor. Dev Biol 112:319-328.

Maffei L, Berardi N, Domenici L, Parisi V, Pizzorusso T (1992) Nerve growth factor (NGF) prevents the shift in ocular dominance distribution of visual cortical neurons in monocularly deprived rats. J Neurosci 12:4651-4662.

Maisonpierre PC, Belluscio L, Squinto S, Ip NY, Furth ME, Lindsay RM, Yancopoulos G (1990) Neurotrophin-3: a neurotrophic factor related to NGF and BDNF. Science 247:1446-1451.

Martin-Zanca D, Barbacid M, Parada LF (1990) Expression of the $t r k$ proto-oncogene is restricted to the sensory cranial and spinal ganglia of neural crest origin in mouse development. Genes Dev 4:638-694.

Menesini-Chen, Chen MJ, Montalcini R (1978) Sympathetic nerve fiber ingrowth in the central nerve system of neonatal rodent upon intracerebral NGF injection. Arch Ital Biol 116:53-84.

Middlemas DS, Lindberg RA, Hunter T (1991) trkB, a neural receptor protein-tyrosine kinase: evidence for a full-length and two truncated receptors. Mol Cell Biol 11:143-153.

Miyata Y, Kashihara Y, Homma S, Kuno M (1986) Effects of nerve growth factor on the survival and synaptic function of Ia sensory neurons axotomized in neonatal rats. $J$ Neurosci 6:2012-2018.

$\mathrm{Mu}$ XJ, Silos-Santiago I, Carroll SL, Snider WD (1993) Neurotrophin receptor genes are expressed in distinct patterns in developing dorsal root ganglia. J Neurosci 13:4029-4041

Olson L (1967) Outgrowth of sympathetic adrenergic neurons in mice treated with a nerve growth factor (NGF). Zellforsch Microsk Anat 81:155-173.

Ruit KG, Elliott JL, Osborne PA, Yan Q, Snider WD (1992) Selective dependence of mammalian dorsal root ganglion neurons on nerve growth factor during embryonic development. Neuron 8:573-587. 
Sandell JH, Masland RH (1988) Photoconversion of some fluorescent markers to a diaminobenzidine product. J Histochem Cytochem 36: 555-559.

Schecterson LC, Bothwell M (1992) Novel roles for neurotrophins are suggested by BDNF and NT-3 mRNA expression in developing neurons. Neuron 9:449-463.

Schnell L, Schneider R, Kolbeck R, Barde YA, Schwab ME (1994) Neurotrophin-3 enhances sprouting of corticospinal tract during the development and after adult spinal cord lesion. Nature 367:170-173.

Sekiya S, Homma S, Miyata Y, Kuno M (1986) Effects of nerve growth factor on differentiation of muscle spindles following nerve lesion in neonatal rats. J Neurosci 6:2019-2025.

Senger DL, Campenot RB(1993) NGF-induced tyrosine phosphorylations of $\mathrm{p} 140^{\text {trk }}$ and ERK in compartmented cultures of rat sympathetic neurons. Soc Neurosci Abstr 19:1305.

Shelton DL, Reichardt LF (1984) Expression of B nerve growth factor gene correlates with the density of sympathetic innervation of effect organs. Proc Natl Acad Sci USA 81:7951-7955.

Simon DK, Oxleary DDM (1992) Development of topographic order in the mammalian retinocollicular projection. J Neurosci 12:12121232.

Snider WD, Johnson EM Jr (1989) Neurotrophic molecules. Ann Neurol 26:489-506.

Snider WD, Palavali V (1990) Early axon and dendritic outgrowth of spinal accessory motor neurons studied with Dil in fixed tissues. $\mathbf{J}$ Comp Neurol 297:227-238.
Snider WD, Zhang L, Yusoof S, Gorukanti N, Tsering C (1992) Interaction between dorsal root axons and their target motor neurons in developing mammalian spinal cord. J Neurosci 12:3494-3508.

Soppet D, Escandon E, Maragos J, Middlemas DS, Reid SW, Blair J, Burton LE, Stanton BR, Kaplan DR, Hunter T, Nikolics K, Parada LF (1991) The neurotrophic factors brain-derived neurotrophic factor and neurotrophin-3 are ligands for the $t r k \mathrm{~B}$ tyrosine kinase receptor. Cell 65:895-903.

Spina MB, Squinto SP, Hyman C (1992) BDNF protects dopamine neurons against 6-OHDA and $\mathrm{MPP}^{+}$toxicity: involvement of the gluthione system. J Neurochem 59:99-106.

Tessier-Lavigne M, Placzek M (1991) Target attraction: are developing axons guided by chemotropism? Trends Neurosci 14:303-310.

Tessier-Lavigne M, Placzek M, Lumsden AGS, Dodd J, Jessell TM (1988) Chemotropic guidance of developing axons in mammalian central nervous system. Nature 336:775.

Tetzlaff W, Leonard CA, Harrington KC (1992) Expression of neurotrophin receptor mRNAs in axotomized facial and rubrospinal neurons. Soc Neurosci Abstr 18:1294.

Tsoulfas P, Soppet D, Escandon E, Tessarol L, Mendozar JL, Rosenthal A, Nikolics K, Parada LF (1993) The rat trkClocus encodes multiple neurogenic receptors that exhibit differential response to neurotrophin-3 in PC 12 cells. Neuron 10:975-990.

Yan Q, Elliott JL, Matheson C, Sun JL, Zhang L, Mu XJ, Rex KL, Snider WD (1993) Influences of neurotrophins on mammalian motoneurons in vivo. J Neurobiol 24:1555-1557. 